\title{
GeoGebra como andaime: uma experiência na resolução de problemas de
}

\section{Geometria}

\section{GeoGebra as scaffolding: an experience in solving Geometry problems}

\author{
Robert Allyson Cavalcante Pinto \\ Universidade Federal Rural de Pernambuco (UFRPE), Programa de Pós-Graduação em \\ Tecnologia e Gestão em Educação a Distância (PPGTEG), Recife, PE, Brasil \\ https://orcid.org/0000-0003-0428-8657, robert.allyson.cavalcante@gmail.com
}

Rodrigo Nonamor Pereira Mariano de Souza

Universidade Federal Rural de Pernambuco (UFRPE), Departamento de Computação (DC), Programa de Pós-Graduação em Tecnologia e Gestão em Educação a Distância (PPGTEG),

Recife, PE, Brasil

https://orcid.org/0000-0003-0694-2886, rodrigo.npmsouza@ufrpe.br

\section{Informações do Artigo \\ Como citar este artigo \\ PINTO, Robert Allyson Cavalcante; SOUZA, Rodrigo Nnonamor Pereira Mariano de. \\ GeoGebra como andaime: uma experiência na resolução de Geometria. REMAT: Revista \\ Eletrônica da Matemática, Bento \\ Gonçalves, RS, v. 7, n. 1, p. e2002, 1 fev. 2021. DOI: \\ https://doi.org/10.35819/remat2021v7i1id4266}

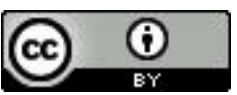

\section{Histórico do Artigo}

Submissão: 15 de junho de 2020.

Aceite: 24 de novembro de 2020.

\section{Palavras-chave}

Educação Matemática

Geometria

Tecnologias Educacionais

Resolução de Problemas

GeoGebra

\section{Resumo}

Apresentamos uma reflexão sobre o uso da ferramenta GeoGebra e da metodologia de resolução de problemas para ensino de Geometria Plana nos níveis fundamental e médio. Nossa proposta consiste em estimular a autonomia do discente por meio de atividades implementadas na plataforma, que chamamos de resoluções guiadas. Uma resolução guiada é uma sequência de passos ou construções geométricas que levam à resolução de um problema, que são apresentados de forma incremental, e documentados com sugestões elaboradas pelo docente. Pretende-se com esse artefato provocar no discente condições de resolver o problema de forma independente, mesmo sem suporte tecnológico. Essa abordagem difere de outras propostas baseadas na ferramenta GeoGebra que encontramos na literatura brasileira, investigada por meio de mapeamento sistemático. Nessas propostas, roteiros pedagógicos completos são apresentados aos estudantes. O principal fundamento teórico de nossa proposta está na teoria sociointeracionista de Vygotsky, na qual exploramos os conceitos de andaime e de Zona de Desenvolvimento Proximal. Avaliamos nossa proposta por meio de intervenções em laboratório de informática com vinte e seis discentes do $9^{\circ}$ ano do Ensino Fundamental e do $1^{\circ}$ ano do Ensino Médio de uma escola particular no município de Teresina, Piauí. Por meio da aplicação de questionários e da observação de participantes, verificamos evolução na capacidade de resolução das atividades propostas, mesmo em papel, após o uso da ferramenta.

\section{Abstract}

\section{Keywords}

Mathematics Education

Geometry

We present a reflection on the use of the GeoGebra tool and the problem solving methodology for teaching Plane Geometry at elementary and high school. Our proposal aims to stimulate student autonomy through activities implemented on the platform, which we call guided resolutions. A guided resolution is a sequence of steps or geometric constructions that lead to the resolution of a problem, which are presented incrementally, and documented with suggestions made by the teacher. Such artifacts are intended to create conditions in students to solve the problem independently, even without technological support. This approach differs from other GeoGebra based proposals found in the Brazilian literature, investigated through systematic mapping, in which complete pedagogical scripts are presented to students. The 
main theoretical foundation of our proposal lies in Vygotsky's social interactionist theory, in which we explore the concepts of scaffolding and the Proximal Development Zone. We evaluated our proposal through interventions in a computer lab with twentysix students from the $9^{\text {th }}$ grade of elementary school and the $1^{\text {st }}$ grade of high school in a private school in the city of Teresina, Sate of Piauí, Brazil. Questionnaires were administered and participant observation was made, , which allowed us to verify the evolution in the problem solving ability for the proposed activities, even on paper, after the use of the tool.

\section{Introdução}

Atualmente, não se concebe a escola como local de transmissão de conteúdo, mas como espaço onde se trabalha a construção da subjetividade do discente, colocando os mesmos como protagonistas de sua própria história. Nessa perspectiva, o uso das Tecnologias de Informação e Comunicação (TIC) pode eliminar barreiras de aprendizagem e potencializar a autonomia do estudante (LAN, 2018). Isso vale, em particular, no contexto do desenvolvimento do raciocínio lógico-matemático, tema no qual inscreve-se o presente trabalho.

O estudo da Matemática é inquestionável na formação do indivíduo, e há várias razões para que um país esteja alinhado com as tendências internacionais de desempenho em Matemática. Todavia, há farto material estatístico e avaliativo que demonstra uma necessidade premente de avanços no ensino de Matemática no Brasil. Um exemplo emblemático é fornecido pelo Programa Internacional de Avaliação de Alunos - PISA, da Organização para a Cooperação e Desenvolvimento Econômico - OCDE. A avaliação de 2015 delineou um quadro de fiasco ao Brasil no que se refere ao conhecimento dos conteúdos da Matemática, o que foi reconhecido pelo Ministério da Educação como uma "tragédia" (OECD, 2016). Entre outras coisas, esse resultado mostra que o conhecimento de $70 \%$ dos discentes brasileiros entre 15 e 16 anos está abaixo de um nível básico. A média dos países membros, em Matemática, é de 490, a do Brasil é 377. Nesse relatório, nosso país ocupa a $66^{a}$ colocação em Matemática dos 72 países participantes. A avaliação de 2019, recém divulgada, não mostrou evolução.

A inovação no contexto do ensino de Matemática é, portanto, um tema no centro dos esforços de educadores e líderes das sociedades educacionais brasileiras. Nessa linha, reflexões e estudos acerca da adoção de novas tecnologias educacionais firmam-se como um tópico fundamental na literatura pedagógica. Segundo Resende e Lara (2019), a produção de Objetos de Aprendizagem aplicados ao ensino de Matemática vem se intensificando desde a década de 2010.

Relativamente ao ensino da Geometria, uma tendência importante consistiu na criação de plataformas de "Geometria Dinâmica", que permitem a realização de construções geométricas e a manipulação de formas geométricas em uma área de trabalho visualmente rica (ISOTANI; BRANDÃO, 2006). Dentre as opções disponíveis, a ferramenta GeoGebra ganhou proeminência e tornou-se objeto de estudo na literatura de Educação Matemática em razão de sua flexibilidade, estabilidade, riqueza de recursos e facilidade de uso. 
A plataforma GeoGebra vem sendo utilizada por docentes de todas as séries como instrumento de mediação pedagógica, fornecendo um ambiente interativo que promove uma aprendizagem instigante, concreta e investigativa, ajudando os estudantes a superar dificuldades para aquisição de conceitos abstratos da Matemática. A mediação pedagógica proporcionada pelo GeoGebra potencializa a aquisição do conhecimento geométrico, e pode servir ao docente no desenvolvimento de práticas educacionais inovadoras e novas estratégias de ensino.

Em consequência, o estudo do GeoGebra como ferramenta educacional tornou-se um tema bastante frequentado na pesquisa de pós-graduação no Brasil. Podemos identificar nesses esforços um pujante viés prático, ao investigar o efeito da aplicação de sequências didáticas elaboradas na ferramenta. Conforme discutiremos adiante, uma tendência geral, nessas pesquisas, consiste na exploração de roteiros de construção que apresentam, explicitamente, as etapas envolvidas, ou de manipulação na plataforma de formas geométricas apresentadas.

A proposta que expomos aqui, oriunda da pesquisa de mestrado de um dos autores (PINTO, 2019), segue essa linha, ao explorar o GeoGebra para ensino de Geometria Plana. Ela tem dois eixos principais: o uso da ferramenta como andaime, com lastro na teoria sociointeracionista de Vygotsky (1991), e a metodologia de resolução de problemas. Essa metodologia forma a base das Olimpíadas de Matemática, populares no mundo todo, que vem demonstrando bons resultados na melhoria da relação do discente com a área (ONUCHIC, 2019).

Por outro lado, nossa proposta enfatiza mais fortemente a autonomia do discente, ao buscar levá-lo a construir caminhos de resolução de um problema de Geometria sem a visualização preliminar, explícita de um roteiro didático. Essa proposta reside, essencialmente, em um tipo de atividade que chamamos de resolução guiada. Trata-se de um processo que parte de um problema, envolvendo uma incógnita (o valor de um ângulo, por exemplo), e que exige uma sequência de construções geométricas e a utilização de resultados fundamentais da Geometria para a determinação desse valor. Mas a construção não é apresentada integralmente ao discente; isso é feito de forma incremental, na plataforma GeoGebra: o discente controla, por meio de botões, o aparecimento de novas etapas da construção. Ademais, cada etapa vem acompanhada por sugestões, elaboradas pelo docente, sobre como prosseguir. O discente é convidado a completar a resolução sozinho, a partir da sugestão. Em caso de bloqueio, pode exibir uma nova etapa.

Realizamos intervenções didáticas com essa proposta em uma população de vinte e seis discentes de uma escola particular de Teresina, Piauí. Nossos resultados, avaliados por meio de observação e questionários, indicam evolução na capacidade de resolução de problemas de Geometria, mesmo sem o apoio da ferramenta GeoGebra (usando lápis e papel).

Nossa abordagem é fortemente centrada no papel do professor, valorizando sua atuação diante de uma ferramenta tecnológica. De fato, a experiência do docente, que identifica os prováveis pontos de dificuldade na resolução de um problema, as passagens em que o discente 
pode deixar de progredir, e possivelmente se frustrar, é crucial para a elaboração de soluções guiadas efetivas, que permitirão ao discente concluir a atividade. Por outro lado, a implementação de uma resolução guiada pode ser uma tarefa penosa para o docente, por necessitar de algum envolvimento da linguagem script nativa do GeoGebra. Discutimos também maneiras de amenizar essa dificuldade.

Este texto está organizado como segue. $\mathrm{Na}$ Seção 2, apresentamos os fundamentos teóricos que sustentam nossa proposta; também incluímos nessa seção uma apresentação rápida da ferramenta GeoGebra, e um mapeamento da produção recente da pós-graduação brasileira sobre ensino de Geometria através do GeoGebra. Na Seção 3, detalhamos o conceito de resolução guiada e discutimos as intervenções realizadas no ambiente escolar. Apresentamos na Seção 4 os resultados dessas intervenções, terminamos com uma conclusão e as referências.

\section{Referencial teórico}

\subsection{Considerações sobre o ensino de Geometria}

A Geometria é um dos pilares da educação matemática, que conecta a Matemática ao mundo material; é também um processo de desenvolvimento da capacidade mental, que contribui para diferentes tipos de pensamento (PIAGET; INHELDER, 1983). O estudo da Geometria leva ao desenvolvimento do reconhecimento de formas e raciocínio matemático avançado, como a descoberta de propriedades e de padrões geométricos. Ideias não geométricas também podem ser representadas geometricamente, como as soluções de equações no plano cartesiano.

A experiência dos discentes em relação à forma e ao espaço é um fenômeno diretamente relacionado ao fato de que eles vivem e agem em um ambiente repleto desses conceitos, de modo que o seu conhecimento é originalmente o resultado da interação com esse mundo. Assim, a Geometria encontra referência na realidade física, e várias ciências usam a complexidade dos padrões geométricos para representar as estruturas do nosso mundo. Em muitos materiais didáticos, essa relação de Geometria com o mundo nem sempre é abordada (GRAVINA, 2001).

Por outro lado, uma forma geométrica não é um conceito simples, se a consideramos como ente matemático formal, abstrato, possuindo propriedades como posição e tamanho. De acordo com Duval (2011), há múltiplas dificuldades pedagógicas a enfrentar na passagem da vivência da Geometria em conexão com o entorno, para a construção de conceitos matemáticos abstratos. Essa construção é fundamental, para que o discente se veja munido de capacidade de generalização e aplicação dos conceitos geométricos na modelagem de situações do mundo que não são necessariamente palpáveis. Essas dificuldades verificam-se particularmente na elaboração de provas matemáticas para problemas de Geometria, em que o desafio é a manipulação de propriedades de formas geométricas em um registro puramente formal, sem uma referência física. 
Evidencia-se então que a prática educacional através de metodologias diferenciadas deve ser considerada. Conforme Duval (2011), o uso de computadores como ferramenta no ensino de Geometria não introduz um novo registro de representação, mas sim uma nova e espetacular função epistemológica, que outros modos de produção não podem facultar, a exploração por simulação. Esse fenômeno ocorre nos pacotes de Geometria Dinâmica, que permitem manipular formas geométricas como se fossem objetos reais (rotações, extensões, mudanças de escala etc.). Nessa linha, o GeoGebra vem sendo estudado na literatura à luz de teorias explicativas do processo de ensino-aprendizagem de Geometria, tais como a teoria dos Registros de Representações Semióticas de Raymond Duval (NOVAK, 2018) e o modelo de van Hiele (ASSAD, 2017).

Desde a década de 1990, diversos autores e fóruns de educação discutem a precariedade do ensino de Geometria nas escolas brasileiras e as consequências desse estado de coisas (PAVANELLO, 1993, LORENZATO, 1995, ALMOULOUD, 2004). Torna-se assim relevante que esse assunto seja revisitado com o apoio de tecnologias educacionais. Esse objetivo está em consonância com a Base Nacional Comum Curricular (BNCC), que preconiza:

[...] softwares de geometria dinâmica têm um papel essencial para a compreensão e utilização das noções matemáticas. Entretanto, esses materiais precisam estar integrados a situações que levem à reflexão e à sistematização, para que se inicie um processo de formalização. (BRASIL, 2017, p. 276).

Essa dimensão da tecnologia, como andaime, é discutida a seguir.

\subsection{Tecnologias educacionais como andaime}

Para Vygotsky, o desenvolvimento humano se dá a partir do pensamento, que se forma na concretude histórico-cultural. O autor defende que "[...] a internalização das atividades socialmente enraizadas e historicamente desenvolvidas constitui o aspecto característico da psicologia humana" (VYGOTSKY, 1991, p. 65). A criança internaliza as ações ocorridas no mundo a sua volta, não de forma passiva, mas interativa, mediada pelo outro, e esse processo de internalização constitui a reconstrução interna de uma operação externa. A aprendizagem integra relações entre as pessoas, em um processo sistematizado que se dá de fora para dentro. Ao docente, cabe a tarefa de organizar, planejar e executar atividades, construindo instrumentos de mediação pedagógica.

A fim de descrever a prática dialógica de auxílio mútuo durante o processo de ensinoaprendizagem, Vygotsky (1991) propõe o conceito de Zona de Desenvolvimento Proximal (ZDP). Uma maneira tradicional (e sucinta) de conceituar a ZDP é como a distância entre o que o discente faz sozinho e o que ele poderá fazer mediado por um sujeito ou uma ferramenta auxiliadora (ZANELLA, 1994). O conceito de ZDP também pode ser entendido por meio do contraste entre dois níveis de desenvolvimento: um se refere às conquistas já efetivadas, o que se chama desenvolvimento real, e o outro, ao desenvolvimento potencial (REGO, 2013). 
O processo de aprendizagem mediada foi também abordado na literatura por intermédio do conceito de andaime. Essa metáfora ilustra a ideia de que apoios didáticos (andaimes) são oferecidos visando impulsionar o discente na resolução de problemas e aquisição de conceitos. $O$ termo andaime, no contexto da Pedagogia, foi proposto por Wood, Bruner e Ross (1976), e sua relação com a teoria vygotskiana de ZDP é matéria de debate. Esse conceito é mais popular na literatura em língua inglesa (scaffolding) do que no Brasil. Bortoni-Ricardo (2008) conceitua andaime como uma medida representativa visível ou audível em que o docente orienta o discente.

A despeito do debate vigente, o conceito de andaime será entendido neste texto simplesmente como o processo mediado que levará o educando a transpor suas ZDPs.

As TICs agregam-se ao pensamento vygotskiano por funcionarem como ferramentas poderosas de mediação pedagógica. O conceito de andaime estende-se a essas ferramentas enquanto objetos mediadores da aprendizagem. As múltiplas possibilidades oferecidas pelas TICs fornecem ao docente campo aberto de elaboração de atividades e roteiros de aprendizagem (COSTA; DUQUEVIZ; PEDROZA, 2015).

Todavia, diversos autores defendem que a tecnologia, per se, é ineficaz sem a atuação propositiva do docente. De Bruyckere, Kirschner e Hulshof (2016) discutem evidências na literatura de que a ferramenta tecnológica é um veículo, mas a essência do ensino permanece nas mãos do docente, de forma que, sem a atuação do mesmo, associando a tecnologia ao conteúdo trabalhado, o processo de ensino-aprendizagem não se realiza plenamente. Mesmo no contexto da pesquisa em Sistemas Tutores Inteligentes, que conheceu nas últimas décadas um avanço exuberante, e que fundamenta diversos sistemas em execução, favorecendo qualidades como feedback imediato e ensino personalizado, há a percepção de que a figura do docente, de sua experiência e sua habilidade na elaboração de roteiros de ensino não pode ser substituída ou dispensada sem prejuízo do processo de ensino-aprendizagem (BAKER, 2016).

A tecnologia como andaime no processo educativo e o papel crucial do docente nesse processo estão na base de nossa experiência com a ferramenta GeoGebra. Ao mesmo tempo em que consideramos o potencial da ferramenta para o ensino de conceitos de Geometria, baseamonos na hipótese de que a resolução guiada elaborada pelo docente é o principal ativo na concretização bem-sucedida da aquisição de um conceito almejado de Geometria.

\subsection{Resolução de problemas}

Evoluindo de uma prática de memorização, típica do início do século $X X$, o ensino de Matemática viu, na década de 1980, florescer o uso de resolução de problemas como ferramenta metodológica inovadora, trazendo um aspecto de materialidade a essa disciplina eminentemente abstrata, instigando e desafiando o discente, criando significados e vínculos entre os conteúdos da Matemática. A resolução de problemas é atualmente uma metodologia muito frequentada como caminho para a aprendizagem de conceitos da Matemática. 
Seu estudo científico teve como marco o livro How to prove it, publicado em 1945 por G. Polya (com uma contribuição posterior de J. Conway), e traduzido no Brasil como "A arte de resolver problemas" (POLYA; CONWAY, 2014). Polya desde então deu importantes contribuições para essa metodologia. Um histórico sobre o desenvolvimento do tema no Brasil é feito por Morais (2015).

Segundo Polya (1962), quando os discentes são levados a resolver problemas, compartilham e discutem suas ideias, promovendo conhecimento matemático, fazendo comparações entre diferentes estratégias e conectando conceitos. Isso ocorre, em particular, entre discentes com diferentes idades e diferentes graus de conhecimento. Evidencia-se aqui uma prática sociointeracionista, na linha do pensamento de Vygotsky. Durante a resolução de um problema, cada etapa vencida significa para o discente um progresso no processo de aprendizagem e a incorporação de novos conteúdos e conceitos. Um estudo aprofundado da resolução de problemas como prática sociointeracionista é conduzido por Leal Junior e Onuchic (2015).

A atividade de resolução de problemas não deve se restringir à seleção e aplicação de regras e procedimentos, previamente estudados e treinados. Polya (1962) descreve quatro etapas para se resolver um problema: compreender o problema; construir uma estratégia de solução; realizar o plano; revisar o processo, examinando a solução. Ou seja, a resolução de problemas é um processo metodológico não-trivial, desafiador, para o qual não se dispõe de um procedimento acabado de construção da solução e que, portanto, requer o desenvolvimento de uma estratégia.

Schoenfeld (2016), que influenciou o desenvolvimento da metodologia de resolução de problemas, afirma que a capacidade de resolver problemas matemáticos pode ser considerada um entendimento matemático. Isso decorre de quatro categorias de conhecimentos que, de acordo com esse autor, caracterizam o bom entendimento da Matemática. Primeiro é a fonte, que é o conhecimento básico de Matemática dos discentes. Em segundo lugar, a heurística, envolvendo habilidades de resolução de problemas. O terceiro é o controle da fonte, ou seja, a capacidade de escolher as informações necessárias. O quarto é o sistema de convicções do discente, sua visão matemática do mundo, que determina a abordagem de um problema.

Nossa experiência explora a aprendizagem de conceitos de Geometria através da resolução de problemas. Essa metodologia é executada com a participação de dois atores, o docente e a ferramenta tecnológica, o primeiro ao elaborar o roteiro didático da resolução, que servirá de andaime ao estudante, o segundo, oferecendo o extraordinário suporte interativo.

\subsection{A ferramenta GeoGebra}

O termo Geometria Dinâmica foi concebido para destacar uma característica básica de certas ferramentas educacionais para ensino de Geometria: a transformação contínua e em tempo real de objetos geométricos, muitas vezes chamada de "arrastamento". Esse recurso permite que 
o usuário possa mover livremente formas geométricas, para observar como as mesmas respondem dinamicamente a essas mudanças, mantendo os relacionamentos definidos entre essas formas.

A ferramenta GeoGebra é um dos principais pacotes de Geometria Dinâmica disponíveis e vem ganhando popularidade no meio acadêmico. Iniciada em 2001 por Markus Hohenwarter em sua pesquisa de mestrado na Universidade de Salzburg (HOHENWARTER, 2002), construído na linguagem Java, o GeoGebra conta hoje com uma comunidade global de desenvolvedores e usuários. É disponibilizada livremente ${ }^{1}$ via navegador ou aplicativo, nos termos da licença GNU GPL. Sua gratuidade contribui com sua popularidade, contrastando com outras plataformas igualmente completas, mas comerciais (Geometer Sketchpad, Cabri II).

O GeoGebra aplica-se à Educação Matemática em níveis diversos, abordando conteúdos de Geometria, Álgebra, Cálculo, Probabilidade, Estatística. Pode servir de apoio ao ensino e aprendizagem em Ciência, Tecnologia e Engenharia. É, todavia, na Geometria que a ferramenta GeoGebra mostra sua maior vocação, através de atividades dinâmicas e visualmente atraentes.

Um histórico da criação dessa ferramenta, bem como dos esforços para a criação de uma comunidade mundial de colaboradores, é apresentado por Hohenwarter, Jarvis e Lavicza (2009). Cabe mencionar que parte dos pesquisadores envolvidos com a ferramenta GeoGebra agrupamse nos chamados "Institutos GeoGebra", que existem em todo o mundo, e também no Brasil, em alguns estados. Conferências nacionais e internacionais dedicadas a trocas de experiências sobre a ferramenta são frequentemente organizadas.

A Figura 1 ilustra a maneira mais direta de acessar o GeoGebra. Embora esteja disponível como aplicativo para computador, a versão on-line, acessível em um navegador, dispensa instalação. Usuários do GeoGebra podem criar um perfil pessoal na ferramenta e armazenar suas construções na nuvem, montando uma biblioteca de atividades, que podem ser compartilhadas com outros usuários.

Figura 1 - Tela inicial do GeoGebra (esquerda) e construção na zona gráfica (direita).
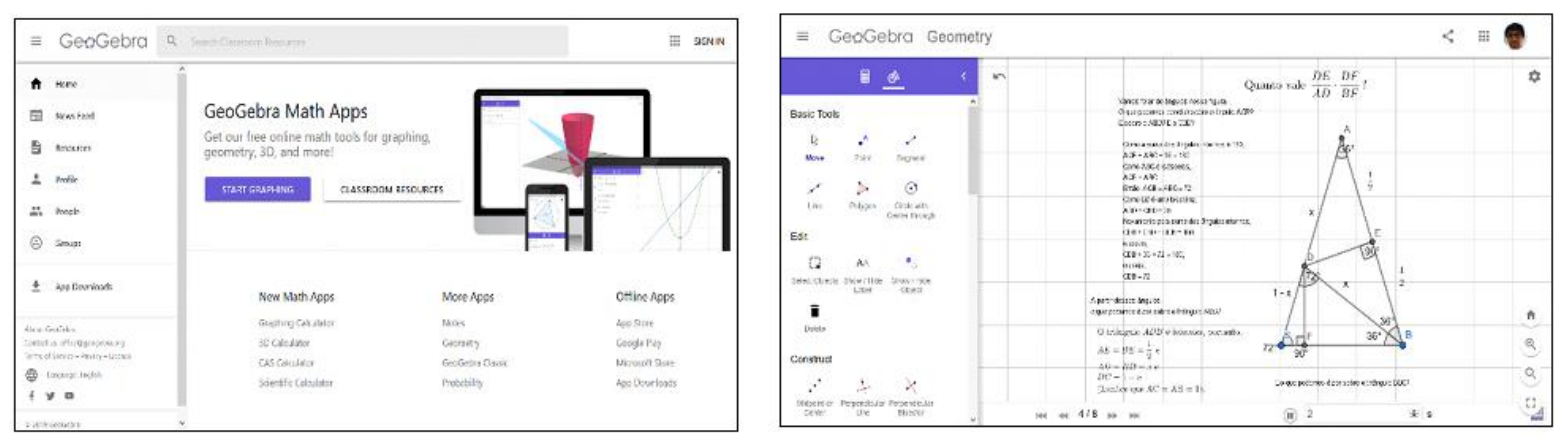

Fonte: Elaboração dos autores (2020).

A Figura 1 mostra à direita uma construção sendo elaborada na zona gráfica. Nessa tela, pode-se visualizar (canto esquerdo) algumas das ferramentas disponíveis: pontos, segmentos,

\footnotetext{
${ }^{1}$ https://www.geogebra.org/
} 
polígonos, circunferências, ângulos etc. No canto superior direito, a foto do usuário mostra que ele está conectado à plataforma através de seu perfil.

Certas construções geométricas podem ser automatizadas com o uso dos recursos disponíveis no menu de ferramentas. Por exemplo, é possível realizar medição de ângulos, construção de bissetrizes, dentre outros. Postulamos que esses recursos devem ser utilizados com parcimônia em um contexto educacional. De fato, a aquisição dos conteúdos da Geometria equivale a habilitar o discente a calcular o valor de um ângulo ou construir uma bissetriz de forma autônoma, mesmo na ausência de suporte computacional. Essa perspectiva forma a base de nossa proposta.

\subsection{Mapeamento da literatura}

Recentemente, diversas dissertações de mestrado produzidas no Brasil, notadamente no programa PROFMAT² ${ }^{2}$, exploram o uso do GeoGebra como instrumento de mediação pedagógica para a fixação de conceitos de Geometria Plana. Tomamos contato com esse panorama através de um mapeamento rápido da literatura no Brasil, que apresentamos a seguir. Nosso objetivo com esse instrumento foi evidenciar nossa contribuição no contexto desse corpo de conhecimento.

Realizamos uma busca no motor Google Scholar com os termos "Geometria Plana", "GeoGebra", "resolução de problemas" e "mediação", intervalos de 2014 a 2017, excluindo o termo "função" (verificamos que há muita literatura voltada ao uso do GeoGebra para ensino de funções). A solicitação devolveu 303 trabalhos de pesquisa (artigos em periódicos, artigos em conferências, dissertações e teses, entre outros), o que mostra que o assunto está bastante aquecido. Após leitura crítica dos resultados e aplicação de critérios de exclusão (duplicações, não adequação ao tema), nove pesquisas de pós-graduação foram selecionadas como representativas desse corpo de produção científica. Todas tratam da resolução de problemas de Geometria Plana com auxílio do GeoGebra como ferramenta mediadora. Optamos por manter somente os trabalhos que contribuam com uma discussão sobre a prática pedagógica, mais do que apresentar demonstrações técnicas das funcionalidades da ferramenta. Os trabalhos consultados são apresentados no Quadro 1.

Quadro 1 - Dissertações de mestrado analisadas em mapeamento da literatura.

\begin{tabular}{|c|c|c|c|}
\hline Título da Dissertação & $\begin{array}{c}\text { Instituição de } \\
\text { Ensino }\end{array}$ & $\begin{array}{c}\text { Ano de } \\
\text { Publicação }\end{array}$ \\
\hline $\begin{array}{c}\text { A utilização do software GeoGebra no processo de } \\
\text { ensino-aprendizagem da Geometria plana }\end{array}$ & $\begin{array}{c}\text { Universidade } \\
\text { Federal de } \\
\text { Alagoas }\end{array}$ & $\begin{array}{c}\text { Manoel Roberto } \\
\text { Alves da Silva }\end{array}$ & 2017 \\
\hline Uso do GeoGebra no Ensino de Geometria Plana \\
no Ensino Básico & $\begin{array}{c}\text { Universidade } \\
\text { Federal de Goiás }\end{array}$ & $\begin{array}{c}\text { Fernando Marçal } \\
\text { Alves }\end{array}$ & 2017 \\
\hline Aprendendo por meio de experiências com & Universidade \\
situações problema & $\begin{array}{c}\text { Rosangela dos } \\
\text { Santos Belo }\end{array}$ & 2016 \\
\hline
\end{tabular}

${ }^{2}$ http://www.profmat-sbm.org.br/ 


\begin{tabular}{|c|c|c|c|}
\hline $\begin{array}{c}\text { Algumas técnicas utilizando o software GeoGebra } \\
\text { no processo de resolução de problemas } \\
\text { geométricos do ensino básico: situações de } \\
\text { máximos e mínimos e lugares geométricos }\end{array}$ & $\begin{array}{c}\text { Paulista Júlio de } \\
\text { Mesquita Filho } \\
\text { Federal de } \\
\text { Roraima }\end{array}$ & $\begin{array}{c}\text { Reginaldo da } \\
\text { Silva Beltrami }\end{array}$ & 2016 \\
\hline $\begin{array}{c}\text { O software GeoGebra como proposta facilitadora } \\
\text { do processo de ensino-aprendizagem da } \\
\text { Geometria plana no Ensino Fundamental }\end{array}$ & $\begin{array}{c}\text { Universidade } \\
\text { Federal de Goiás }\end{array}$ & $\begin{array}{c}\text { Leonlívier Max } \\
\text { Garcia Pereira }\end{array}$ & 2015 \\
\hline $\begin{array}{c}\text { Constituição de zona de desenvolvimento proximal } \\
\text { na aprendizagem de conceitos geométricos em } \\
\text { alunos de anos iniciais tendo o GeoGebra como } \\
\text { instrumento mediador }\end{array}$ & $\begin{array}{c}\text { Universidade } \\
\text { Federal de Santa } \\
\text { Maria }\end{array}$ & $\begin{array}{c}\text { Siméia Tussi } \\
\text { Jacques }\end{array}$ & 2015 \\
\hline $\begin{array}{c}\text { Resolução de Problemas de Congruência de } \\
\text { Triângulos com auxílio do Software GeoGebra }\end{array}$ & $\begin{array}{c}\text { Universidade } \\
\text { Federal do } \\
\text { Ceará }\end{array}$ & $\begin{array}{c}\text { Francisco Ricardo } \\
\text { Nogueira de } \\
\text { Vasconcelos }\end{array}$ & 2015 \\
\hline $\begin{array}{c}\text { Tópicos de Geometria plana com o software } \\
\text { GeoGebra: proposta de sequências didáticas }\end{array}$ & $\begin{array}{c}\text { Federal do } \\
\text { Espírito Santo }\end{array}$ & $\begin{array}{c}\text { Luciana Bahiense } \\
\text { Fiorotti }\end{array}$ & 2014 \\
\hline $\begin{array}{c}\text { Teorema de Pitágoras: algumas } \\
\text { Estadual } \\
\text { extensões/generalizações e atividades com o } \\
\text { Software GeoGebra }\end{array}$ & $\begin{array}{c}\text { Paulista Júlio de } \\
\text { Mesquita Filho }\end{array}$ & João Evangelista \\
Brito da Silva & 2014 \\
\hline
\end{tabular}

Fonte: Elaboração dos autores (2020).

As experiências relatadas contribuem em múltiplas dimensões com o processo de ensino da Geometria. Identificamos no conjunto desses trabalhos os seguintes desenvolvimentos:

- Experiências de visualização, para fixação de definições envolvendo figuras geométricas e construções;

- Experiências com situações-problema para fixação de conceitos geométricos fundamentais, como área e perímetro;

- Roteiros didáticos para exploração dos conceitos de máximo, mínimos e lugares geométricos;

- Prática com os recursos da plataforma envolvendo primitivas da Geometria Euclidiana (pontos, retas, planos);

- Divulgação da ferramenta através de minicursos;

- Discussão do conceito de ZDP em atividades com a plataforma;

- Investigação do Teorema de Pitágoras.

Verificamos nos mesmos uma tendência em explorar roteiros de construção explícitos roteiros didáticos - nos quais os discentes têm acesso a todas as etapas e aspectos, além da automatização de cálculos através do GeoGebra. Um exemplo dessa constatação, tirado de Fiorotti (2014), é apresentado na próxima seção.

Não discutimos o valor pedagógico dessas práticas; ao mesmo tempo, entendemos que ainda há espaço no Brasil para avanços no uso pedagógico do GeoGebra. Dessa forma, 
apresentamos uma exploração dos roteiros didáticos fortemente baseada na autonomia do aluno, em atenção à necessidade de estimular a apropriação do conteúdo para a elaboração de uma resolução original. Nossa proposta consiste na apresentação de um problema de Geometria, mas não da sua solução. A resolução é deixada para o aluno, mas não totalmente: ele conta, como andaime, com um roteiro elaborado pelo docente, roteiro que pode abandonar após visualização parcial, e prosseguir sozinho. Esses roteiros são o que chamamos de resoluções guiadas, conceito que explicamos e exemplificamos na próxima seção.

\section{Metodologia}

\subsection{Resoluções guiadas}

O roteiro aludido na seção anterior, que chamamos de roteiro ou resolução guiada, consiste das etapas de uma possível resolução, cada uma acompanhada por um comentário do docente, que sugere a próxima etapa e elucida pontos potenciais de bloqueio. O discente navega na resolução através de botões na janela gráfica e é convidado a progredir de forma autônoma, com base nos comentários do docente; havendo bloqueio, pode pedir a exibição da próxima etapa.

Nossa principal preocupação, nessa experiência, é dar ao professor meios de construir andaimes no GeoGebra, que conduzam o estudante a resolver um problema. Entendemos que a frustração oriunda de uma dificuldade impeditiva na conclusão de uma resolução pode atentar criticamente contra o aprendizado; por outro lado, a conclusão de uma resolução completa, mesmo por intermédio de um andaime, traz confiança ao aluno, influindo em sua relação com o assunto.

Vamos expor o conceito de resolução guiada por meio de um exemplo, tirado ipsis litteris de Pinto (2019). Para mais subsídios, o leitor encontra na mesma dissertação outras duas resoluções guiadas, elaboradas pelos autores, também descritas passo a passo.

Nosso exemplo parte da atividade ilustrada na Figura 2, tirada de Fiorotti (2014):

Figura 2 - Questão 1 da dissertação de mestrado de Fiorotti (2014).

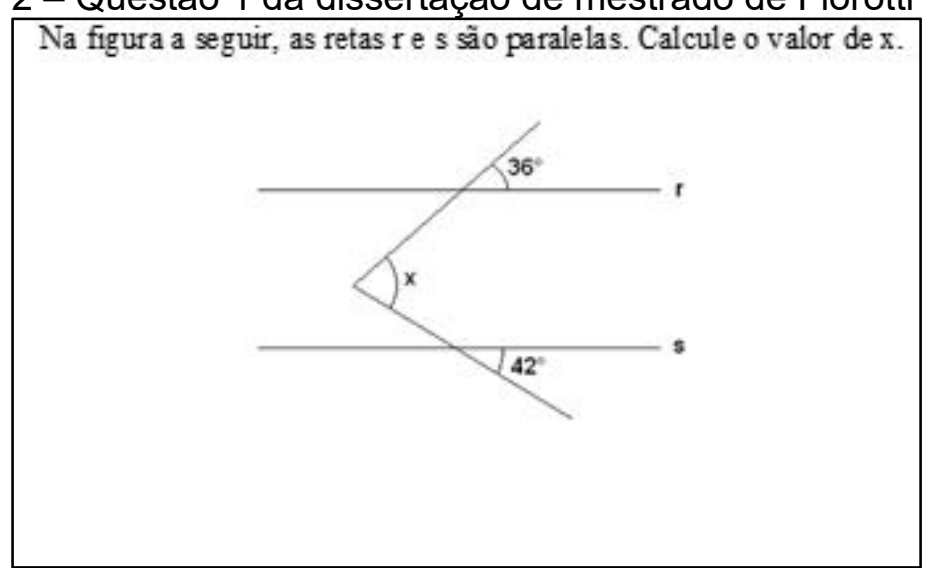

Fonte: Fiorotti (2014, p. 27). 
O roteiro didático apresentado por Fiorotti (2014) consiste em uma sequência de instruções (ferramentas disponíveis no GeoGebra), levando o discente à construção da figura. Finalmente, o valor do ângulo é calculado diretamente através da ferramenta de medição do GeoGebra.

Nossa proposta parte da figura já construída, que é fornecida ao estudante na janela gráfica. O problema consiste no cálculo do ângulo, sem uso da ferramenta de medição do GeoGebra, mas através de construções geométricas que o estudante deve executar.

A Figura 3 apresenta a primeira tela da resolução guiada que elaboramos para essa atividade.

Figura 3 - Primeira tela da resolução guiada proposta para a atividade ilustrada na Figura 2.

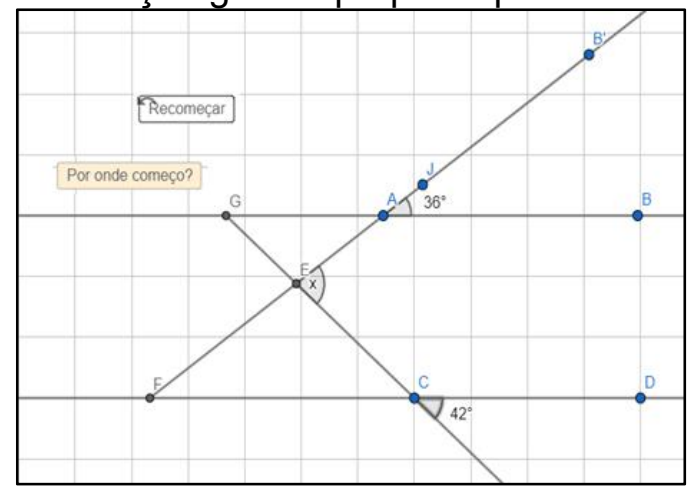

Fonte: Elaboração dos autores (2020).

O estudante depara-se nessa tela com a figura já construída e com dois botões: o primeiro, "Recomeçar", permite apagar todas as construções efetuadas, voltando a essa tela inicial; o botão "Por onde começo" apresenta a primeira etapa da resolução guiada. Se o estudante não visualizar uma estratégia para resolver o problema, ou seja, para encontrar o ângulo, pode acionar esse botão.

A Figura 4 ilustra as demais etapas do roteiro guiado. Conforme discutimos, cada uma traz um comentário do docente, sugerindo o próximo passo para uma possível solução e um botão para exibição da próxima etapa. Partindo da sugestão, o aluno pode prosseguir sozinho ou então acionar o botão, caso ainda não visualize um caminho. A passagem a uma nova etapa envolve a ocultação ou modificação de objetos presentes na tela, e a exibição de novos objetos e comentários.

Realizamos intervenções pedagógicas em uma escola com o roteiro apresentado acima e outros dois roteiros, para questões mais difíceis, oriundas do ENEM e do Concurso Público de Admissão ao Colégio Naval (veja discussão na próxima seção). Nessas intervenções, as resoluções guiadas foram preparadas pelos autores, usando para isso código script nativo da plataforma para ocultar e exibir objetos de acordo com ações executadas pelo discente.

Com relação à elaboração de uma resolução guiada, coloca-se a necessidade de se enfrentar barreiras técnicas de implementação na plataforma GeoGebra. Por outro lado, entendemos que o docente de Matemática é o especialista competente para desenhar caminhos pedagógicos que possam levar à aquisição de um conteúdo. Em Pinto (2019) apresentamos um 
conjunto de recomendações e um script escrito na linguagem Perl, constituindo subsídios para que o docente possa elaborar suas próprias resoluções guiadas de forma autônoma, sem necessidade de implementação de código nativo GeoGebra e sem necessidade de recorrer a apoio técnico.

Figura 4 - Demais etapas da resolução guiada iniciada na Figura 3.

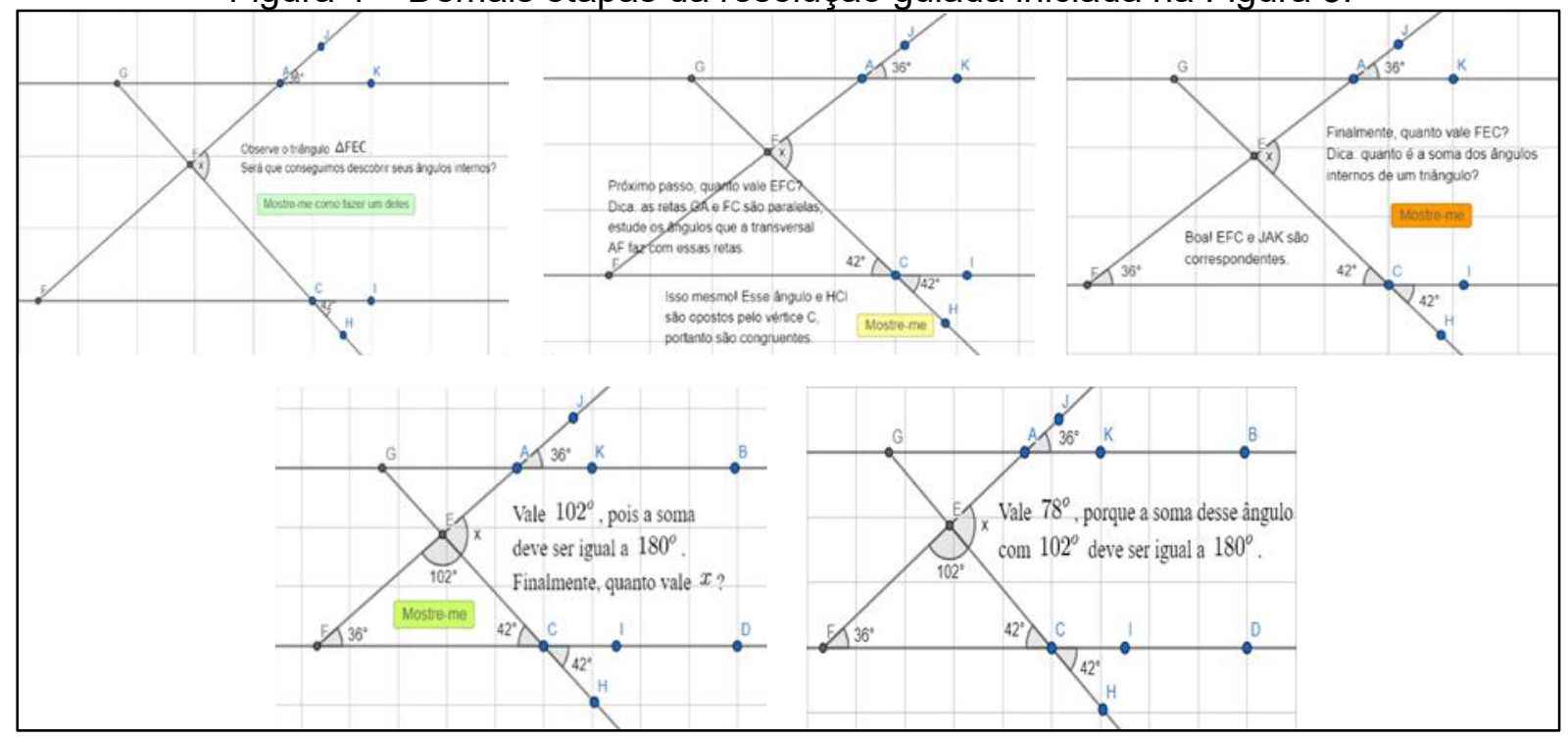

Fonte: Elaboração dos autores (2020).

\subsection{Intervenções no espaço escolar}

Para Marconi e Lakatos (2017), a pesquisa descritiva tem como objetivo reunir e analisar dados levantados. A presente pesquisa é descritiva, pois observamos, registramos e analisamos informações coletadas. As intervenções em ambiente escolar, nas quais avaliamos a aplicação de atividades com o GeoGebra, constituem pesquisa de campo. Utilizamos como instrumentos de avaliação dois questionários, aplicados antes e depois dessas intervenções.

As intervenções ocorreram em uma escola particular, situada em um bairro de classe média baixa na cidade de Teresina PI, em sala de aula e em laboratório de Informática da escola. O cenário educacional escolhido foi inicialmente o $9^{\circ}$ ano do Ensino Fundamental. Por sugestão do docente de Matemática, agregou-se a essa atividade, ainda no início, a turma do $1^{\circ}$ ano do Ensino Médio. Desse público, participaram efetivamente vinte e seis discentes, dezessete do $9^{\circ}$ ano do Ensino Fundamental e nove do $1^{\circ}$ ano do Ensino Médio. As turmas trabalharam separadamente.

Os conteúdos trabalhados foram conceitos geométricos básicos: pontos no plano cartesiano, retas no plano cartesiano, retas paralelas, retas perpendiculares, intersecção de retas, ponto médio de um segmento, mediatriz de um segmento, ângulos, classificação de um ângulo, bissetriz, circunferência, figuras geométricas. Ao estudar as relações métricas no triângulo retângulo tivemos a aplicação do Teorema de Pitágoras em algumas construções.

As intervenções começaram a ser realizadas no início de maio de 2019 e foram divididas em cinco etapas, estendendo-se até o mês de junho de 2019. Cada etapa constituiu-se de duas 
visitas à escola, em dois dias da semana, na terça-feira com duração de duzentos minutos e na quinta-feira com duração de cem minutos, uma visita para cada turma.

Na primeira etapa, em sala de aula, fizemos uma apresentação da pesquisa, sua finalidade, instituição de origem, disciplina abordada, conteúdo programático e proposta geral do uso de uma ferramenta tecnológica. Apresentamos também a ferramenta GeoGebra, e aplicamos o questionário inicial, para avaliação do perfil dos sujeitos participantes, que pode ser consultado em Pinto (2019). Buscamos com esse questionário:

- Delimitar o nível de conhecimento do conteúdo de Geometria;

- Avaliar o nível de conhecimento de Informática, seu letramento digital, destacando a frequência, o local e a finalidade que os discentes participantes destinam à utilização de computadores;

- Indagar quanto à aplicação de tecnologias como meio na aprendizagem, buscando levantar percepções sobre o uso desses recursos como apoio às atividades desenvolvidas em sala de aula;

- Descobrir contatos prévios com a ferramenta GeoGebra.

As intervenções seguintes aconteceram no laboratório. Nelas, trabalhamos efetivamente com a resolução de problemas, aplicando nossas resoluções guiadas. Elencamos três problemas, em nível crescente de dificuldade: um oriundo de Fiorotti (2014) (precisamente o roteiro apresentado na Seção 3.1), um do ENEM 2011 e um do Concurso Público de Admissão ao Colégio Naval 2017. Os problemas e as resoluções guiadas associadas podem ser consultados em Pinto (2019).

No último encontro, aplicamos o questionário pós-experiência, com o qual buscamos analisar uma mudança de atitude dos discentes após nossa intervenção.

As etapas de resolução de problemas seguiram o seguinte protocolo:

- Cinco minutos de apresentação de aspectos da plataforma GeoGebra, nas quais continuamente destacamos as principais barras de ferramentas, através de demonstrações, datashow e vídeos selecionados no YouTube;

- Cinco minutos de ambientação, nos quais os discentes estiveram livres para criar figuras à vontade e descobrir o potencial da ferramenta;

- Vinte minutos para resolver o problema de Geometria proposto da atividade. Essa resolução se dava de forma individual e utilizando somente o enunciado do problema, caderno, lápis e borracha, sem ajuda dos guias no GeoGebra;

- Quarenta minutos envolvendo explicação do processo de resolução guiada, e a efetiva realização da resolução guiada, no GeoGebra, culminando na resolução do problema;

- Intervalo de cinco minutos para descanso; 
- Vinte minutos para nova tentativa de resolução no caderno, individualmente, sem contato com o GeoGebra;

- Por fim, cinco minutos para considerações finais.

Como comentamos, as resoluções guiadas foram elaboradas pelos autores.

\section{Resultados e discussão}

O questionário de avaliação de perfil trouxe-nos uma percepção sobre o conhecimento dos discentes acerca de software educacional e sua relação com a disciplina de Matemática.

Relativamente ao uso do computador e do smartphone, constatou-se que $73 \%$ dos participantes utilizam computador e $84 \%$ utilizam smartphone com frequência. Dos usuários que acessam com frequência o computador, $63 \%$ utilizam em casa, $31 \%$ usam em lan houses e $6 \%$ na escola, e com relação ao smartphone $81 \%$ utilizam em casa e $19 \%$ em outros lugares. Com relação a periodicidade, dos $73 \%$ que usam o computador, $21 \%$ usam todos os dias, $16 \%$ utilizam de quatro a seis vezes por semana e 53\% acessam de uma a três vezes por semana. Dos $84 \%$ que utilizam smartphone, $100 \%$ acessam todos os dias. Quando perguntado sobre a finalidade do uso dessas ferramentas, para essa pergunta permitimos mais de uma opção, $42 \%$ utilizam o computador para pesquisa, 34\% utilizam para estudar, $19 \%$ para entretenimento e $5 \%$ para trabalho. Com relação ao smartphone, 52\% usam para o entretenimento, $27 \%$ para pesquisa, $21 \%$ para estudo.

Em pergunta aberta, indagamos acerca da utilização de software educacional. Cinco discentes afirmaram desconhecer a utilização de recursos tecnológicos digitais para apoio à aprendizagem, e vinte e um já utilizaram Duolingo e o Minecraft em atividades escolares e extraclasse. As respostas evidenciam desconhecimento sobre o uso de ferramentas educacionais no ensino da Matemática e foi unânime o desconhecimento sobre a ferramenta GeoGebra.

Ao perguntarmos sobre o nível de dificuldade no aprendizado de Matemática, $31 \%$ afirmaram ser muito difícil, $35 \%$ afirmaram ser difícil, $27 \%$ falaram que é médio o nível de dificuldade e somente $7 \%$ disseram ser fácil. Ou seja, dos vinte e seis discentes participantes da pesquisa, somente dois afirmaram se sentir confortáveis ao estudarem a disciplina. Esses valores são sumarizados na Figura 5.

Figura 5 - Nível de dificuldade do estudo de Matemática (Questionário A).

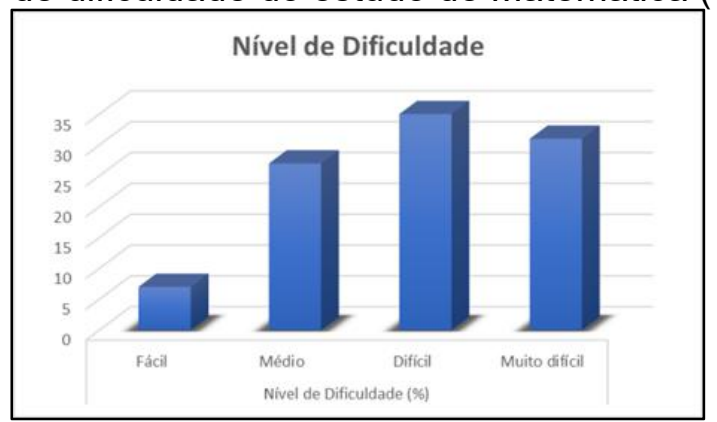

Fonte: Elaboração dos autores (2020). 
Com relação aos recursos utilizados para estudar os conteúdos de Matemática, para este quesito eles puderam selecionar mais de uma alternativa, $74 \%$ utilizam material da Internet, livros e as anotações de aula e somente $16 \%$ procuram alguma ferramenta educativa ou outros meios.

Nosso principal resultado refere-se a uma melhoria observada na resolução das questões propostas utilizando somente lápis e papel. Nas três atividades, os discentes apresentaram dificuldades impeditivas quando confrontados pela primeira vez com a questão, antes do uso do GeoGebra. Após a intervenção, observamos que a maior parte conseguiu completar a resolução de forma autônoma, individualmente, e sem o uso da ferramenta.

A Figura 6 apresenta os números para a Atividade 1. Sendo a atividade mais simples, cerca de um quarto dos alunos conseguiu resolver na primeira tentativa, com lápis e papel. Após a experiência com a ferramenta, somente um discente não concluiu em nova tentativa.

Figura 6 - Resolução com lápis e papel da Atividade 1, antes (esquerda) e depois (direita) da prática com resolução guiada no GeoGebra.
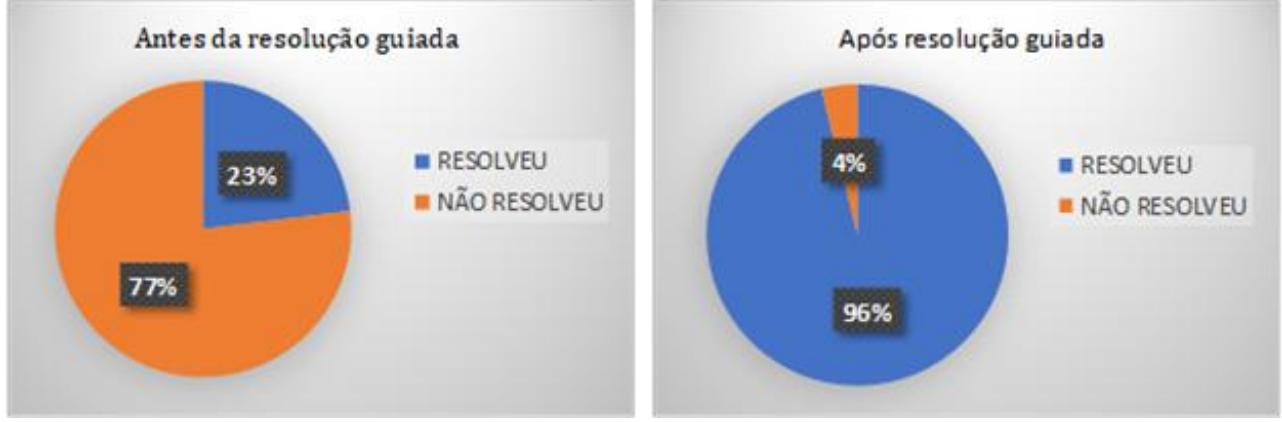

Fonte: Elaboração dos autores (2020).

Para as duas outras questões, nenhum discente conseguiu completar a resolução na primeira tentativa. A Figura 7 mostra os números de sucesso após a experiência com a resolução guiada. Mesmo se tratando de questões mais difíceis, a maioria dos discentes conseguiu reproduzir a resolução com lápis e papel, após a experiência no GeoGebra.

Figura 7 - Resolução com lápis e papel, depois da prática com resolução guiada no GeoGebra, para as atividades 2 e 3.

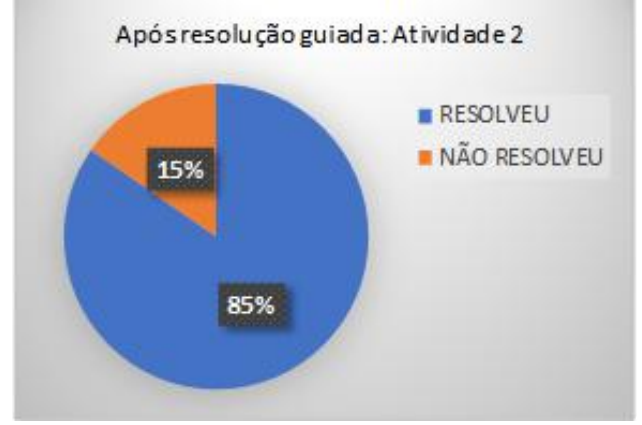

Após resolução guiada: Atividade 3

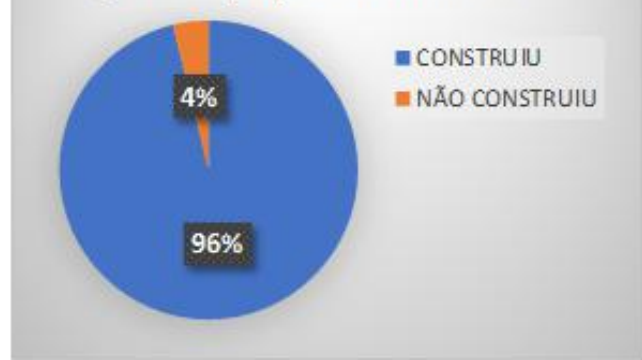

Fonte: Elaboração dos autores (2020).

O questionário de avaliação pós-experiência evidenciou um entusiasmo relativamente ao uso da ferramenta, o que pode influir no relacionamento com a disciplina. Os relatos a seguir, observados em questão aberta, são característicos dessa percepção: 
É muito funcional tanto para o professor quanto para o aluno.

Achei muito importante porque eu tinha uma outra opção a não ser o professor para me ajudar.

Eu me senti criativo pois eu consegui construir as figuras.

Para 96\% dos discentes, a utilização do GeoGebra em laboratório ajudou na elaboração da resolução dos problemas propostos. Em relação ao uso do GeoGebra, 54\% afirmaram que tiveram dificuldades em operar as funcionalidades da ferramenta, e 46\% declararam que não encontraram dificuldades. Cabe destacar que, para se manusear uma ferramenta tecnológica, inicialmente se faz necessário conhecimento básico da mesma. Assim, o uso da ferramenta se tornou mais natural ao longo do tempo e postulamos que com alguma experiência, essa opinião seria abandonada.

\section{Considerações finais}

Após observar que a prática de sequências didáticas na ferramenta GeoGebra é um tema recorrente na pesquisa sobre ensino de Geometria no Brasil, propusemos agregar a essas reflexões uma proposta que chamamos de resolução guiada. Trata-se de um roteiro de solução de um problema de Geometria - de forma que nossa proposta baseia-se na metodologia de resolução de problemas - elaborado por um docente, e cujos passos são apresentados de forma incremental, na plataforma, contando, ainda, com comentários (elaborados pelo docente) que sugerem os próximos passos e estimulam o estudante a continuar por conta própria. Buscamos dessa forma potencializar o caráter mediador da ferramenta, sua função de andaime, com o objetivo de incentivar a autonomia do estudante, sua capacidade de resolver um problema individualmente, mesmo com lápis e papel, o que atesta a compreensão de conceitos e a elaboração de raciocínios.

Realizamos uma intervenção didática em uma escola particular, aplicando três resoluções guiadas preparados por nós. Observamos evolução na capacidade de resolver os problemas propostos após a experiência com a resolução guiada, e isso somente com lápis e papel. $\mathrm{O}$ entusiasmo dos estudantes envolvidos também foi um aspecto da intervenção. Esses resultados apontam para um potencial pedagógico da proposta, a ser explorado em trabalhos futuros.

Como trabalhos futuros, cabe primeiramente desenvolver possibilidades para que os docentes possam implementar resoluções guiadas com facilidade. Como mencionamos, tivemos de utilizar código script nativo da plataforma em nossas experiências, o que é impeditivo para o docente de Matemática. Em Pinto (2019) apresentamos um script na linguagem Perl que fornece ao docente a possibilidade de desenhar os passos de seu roteiro no GeoGebra e anotar as ações que levam às transições entre etapas (aparecimento e remoção de objetos geométricos) em um arquivo texto; o script aplica esses comandos na atividade, gerando uma resolução guiada. 
Entendemos que essa ideia pode ser melhor desenvolvida, resultando, eventualmente, na incorporação do recurso dentro da plataforma GeoGebra. Outra ação futura desejável consiste em investigar com mais acuidade as possibilidades e limitações de nossa proposta, trabalhando, por exemplo, com grupos de controle e buscando estabelecer em que medida a prática com as resoluções leva a uma fixação efetiva de conceitos (isso poderia ser feito propondo problemas diferentes, mas relacionados ao considerado na resolução, após a prática com a plataforma).

\section{Referências}

ALMOULOUD, S. A. A geometria na escola básica: que espaços e formas tem hoje. In: ENCONTRO PAULISTA DE EDUCAÇÃO MATEMÁTICA, 7., São Paulo, SP, 1994. Anais [...], São Paulo, 2004.

ASSAD, A. Usando o geogebra para analisar os níveis do pensamento geométrico dos alunos do ensino médio na perspectiva de Van Hiele. Orientadora: Luciane Grossi. 2017. $161 f$. Dissertação (Mestrado Profissional em Matemática) - Universidade Estadual de Ponta Grossa, Ponta Grossa, PR, 2017. Disponível em: http://tede2.uepg.br/ispui/handle/prefix/2444. Acesso em: 1 ago. 2020.

BAKER, R. S. Stupid Tutoring Systems, Intelligent Humans. International Journal of Artificial Intelligence in Education, v. 26, n. 2, p. 600-614, 2016. DOI: https://doi.org/10.1007/s40593-0160105-0.

BORTONI-RICARDO, S. M. O Professor Pesquisador: Introdução à Pesquisa Qualitativa. São Paulo: Parábola Editorial, 2008.

BRASIL. Ministério da Educação. Base Nacional Comum Curricular - BNCC, versão aprovada pelo CNE, novembro de 2017. Disponível em: http://basenacionalcomum.mec.gov.brl. Acesso em: 10 jun. 2020.

COSTA, S. R. S.; DUQUEVIZ, B. C.; PEDROZA, R. L. S. Tecnologias Digitais como instrumentos mediadores da aprendizagem dos nativos digitais. Psicologia Escolar e Educacional, Maringá, v. 19, n. 3, p. 603-610, set./dez. 2015. DOI: https://doi.org/10.1590/2175-3539/2015/0193912.

DE BRUYCKERE, P.; KIRSCHNER, P. A.; HULSHOF, C. D. Technology in Education: What Teachers Should Know. American Educator, v. 40, n. 1, p. 12-18, 2016. Disponível em: https://eric.ed.gov/?id=EJ1094203. Acesso em: 1 ago. 2020.

DUVAL, R. Ver e ensinar a matemática de outra forma - entrar no modo matemático de pensar: os registros de representações semióticas. São Paulo: PROEM, 2011.

FIOROTTI, L. B. Tópicos de Geometria Plana com o Software Geogebra: Proposta de Sequências Didáticas. Orientador: Valmecir Antonio dos Santos Bayer. 2014. 50f. Dissertação (Mestrado Profissional em Matemática) - Universidade Federal do Espírito Santo, Vitória, ES, 2014. Disponível em:

http://portais4.ufes.br/posgrad/teses/tese 7684 DISSERTA\%C7\%C3O Luciana\%20Bahiense.pdf. Acesso em: 1 ago. 2020.

GRAVINA, M. A. Os ambientes de geometria dinâmica e o pensamento hipotético-dedutivo. Orientadora: Lucila Maria Costi Santarosa. 2001. 277f. Dissertação (Mestrado em Informática na Educação) - Universidade Federal do Rio Grande do Sul, Porto Alegre, RS, 2001. Disponível em: https://lume.ufrgs.br/handle/10183/2545. Acesso em: 1 ago. 2020. 
HOHENWARTER, M. GeoGebra: ein Softwaresystem für dynamische Geometrie und Algebra der Ebene. Dissertação - Naturwissenschaftlichen Fakultät, Paris-Lodron-Universität Salzburg, Salzburg, 2002.

HOHENWARTER, M.; JARVIS, D.; LAVICZA, Z. Linking Geometry, Algebra, and Mathematics Teachers: GeoGebra Software and the Establishment of the International GeoGebra Institute. International Journal for Technology in Mathematics Education, v. 16, n. 2, p. 83-87, 2009.

ISOTANI, S.; BRANDÃO, L. O. Como Usar a Geometria Dinâmica? O Papel do Professor e do Aluno Frente às Novas Tecnologias. In: WORKSHOP DE INFORMÁTICA NA ESCOLA, 7., Campo Grande, MS, jul. 2006. Anais [...]. Sociedade Brasileira de Computação: 2006, p. 120-128. Disponível em: https://www.br-ie.org/pub/index.php/wie/article/view/882. Acesso em: 01 fev. 2021.

LAN, Y-J. Technology enhanced learner ownership and learner autonomy through creation. Educational Technology Research and Development, v. 66, p. 859-862, 12 jun. 2018. DOI: https://doi.org/10.1007/s11423-018-9608-8.

LEAL JUNIOR, L. C.; ONUCHIC, L. R. Ensino e Aprendizagem de Matemática através da Resolução de Problemas como Prática Sociointeracionista. Bolema: Boletim de Educação Matemática, Rio Claro, v. 29, n. 53, p. 955-978, dez. 2015. DOI: https://doi.org/10.1590/1980$\underline{4415 \mathrm{v} 29 \mathrm{n} 53 \mathrm{a} 09 .}$.

LORENZATO, S. Por que não ensinar Geometria? A Educação Matemática em Revista, Blumenau, v. 4, ano 3, p. 3-13, 1995.

MARCONI, M. A.; LAKATOS, E. M. Fundamentos de Metodologia Científica. São Paulo: Atlas, 2017.

MORAIS, R. S. O processo constitutivo da Resolução de Problemas como uma temática da pesquisa em Educação Matemática: um inventário a partir de documentos dos ICMEs. Orientadora: Lourdes de la Rosa Onuchic. 2015. 471f. Tese (Doutorado em Informática na Educação) - Universidade Estadual Paulista, Rio Claro, SP, 2015. Disponível em: https://repositorio.unesp.br/handle/11449/132220. Acesso em: 1 ago. 2020.

NOVAK, F. I. L. O ambiente dinâmico GeoGebra para o desenvolvimento de aspectos específicos da aprendizagem em Geometria segundo Raymon Duval: olhares, apreensões e desconstrução dimensional. Orientadora: Celia Finck Brandt. 2018. 149f. Dissertação (Mestrado em Educação) - Universidade Estadual de Ponta Grossa, Ponta Grossa, 2018. Disponível em: http://tede2.uepg.br/jspui/handle/prefix/2641. Acesso em: 20 dez. 2020.

OECD. PISA 2015 Results: Excellence and Equity in Education. v. I. Paris: OECD Publishing, 2016. DOI: http://dx.doi.org/10.1787/9789264266490-en.

ONUCHIC, L. R. Resolução de Problemas: Teoria e Prática. Jundiaí: Paco Editorial, 2019.

PAVANELLO, R. M. O abandono do ensino da geometria no Brasil: causas e consequências. Zetetiké, Campinas, v. 1, n. 1, p. 7-17, jan./dez. 1993. Disponível em: https://periodicos.sbu.unicamp.br/ojs/index.php/zetetike/article/view/8646822. Acesso em: 1 fev. 2021.

PIAGET, J.; INHELDER, B. Gênese das Estruturas Lógicas Elementares. Rio de Janeiro: Zahar, 1983. 
PINTO, R. Geogebra como andaime: uma experiencia na resolução de problemas de Geometria. Orientador: Rodrigo Nonamor Pereira Mariano de Souza. 2019. 125f. Dissertação (Mestrado em Tecnologia e Gestão em Educação a Distância) - Programa de Pós-Graduação em Tecnologia e Gestão em Educação a Distância, Universidade Federal Rural de Pernambuco, Recife, 2019.

POLYA, G.; CONWAY, J. H. How to Solve It: A New Aspect of Mathematical Method. Princeton, Nova Jersey: Princeton University Press, 2014.

POLYA, G. Mathematical Discovery: On Understanding, Learning, and Teaching Problem Solving. Hoboken, Nova Jersey: John Wiley \& Sons, 1962.

REGO, T. C. Vygotsky: Uma perspectiva histórico-cultural da educação. Petrópolis: Editora Vozes, 2013.

RESENDE, B.; LARA, I. C. M. Objetos de Aprendizagem e contribuições para Educação Matemática: mapeamento teórico de artigos acadêmicos. REMAT: Revista Eletrônica da Matemática, Bento Gonçalves, v. 5, n. 1, p. 11-24, 2019. DOI:

https://doi.org/10.35819/remat2019v5i1id3188.

SCHOENFELD, A. H. Mathematical problem solving. Cambridge, Massachusetts: Academic Press, 2016.

VYGOTSKY, L. S. A formação social da mente. São Paulo: Martins Fontes, 1991.

WOOD, D.; BRUNER, J. S.; ROSS, G. The role of tutoring in problem solving. Journal of Child Psychology and Psychiatry, v. 17, n. 2, p. 89-100, 1976. DOI: https://doi.org/10.1111/j.14697610.1976.tb00381.x.

ZANELLA, A. V. Zona de desenvolvimento proximal: análise teórica de um conceito em algumas situações variadas. Temas em Psicologia, Ribeirão Preto, v. 2, n. 2, p. 97-110, ago. 1994.

Diponível em: http://pepsic.bvsalud.org/scielo.php?script=sci arttext\&pid=S1413389X1994000200011\&lng=pt\&nrm=iso\&tlng=pt. Acesso em: 1 fev. 2021. 